\title{
Measuring and suppressing the oxidative damage to DNA during $\mathrm{Cu}(\mathrm{I})$-catalyzed azide-alkyne cycloaddition
}

\author{
Gary R. Abel, Jr., ${ }^{\dagger}$ Zachary A. Calabrese,${ }^{\dagger}$ Jeffrey Ayco, ${ }^{\dagger}$ Jason E. Hein, ${ }^{\dagger, *}$ and Tao Ye ${ }^{\dagger, *}$ \\ $\dagger$ Chemistry \& Chemical Biology, School of Natural Sciences, University of California, Merced, 5200 N Lake Rd., \\ Merced, CA 95343, USA \\ $\ddagger$ Department of Chemistry, UBC Faculty of Science, The University of British Columbia, 2036 Main Mall, Vancouver, \\ BC Canada V6T 1 Z1 \\ *E-mail: jhein@chem.ubc.ca, tao.ye@ucmerced.edu
}

\section{Table of contents}

Materials and methods. S2

Table of DNA sequences used. S2

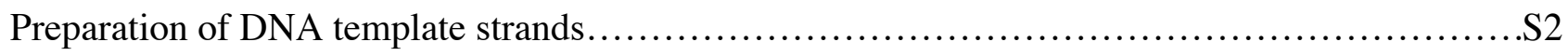

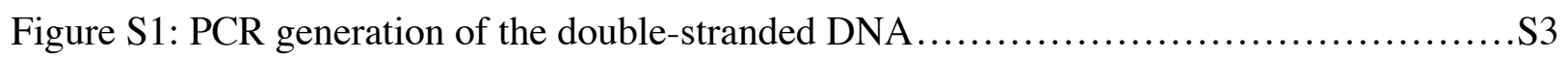

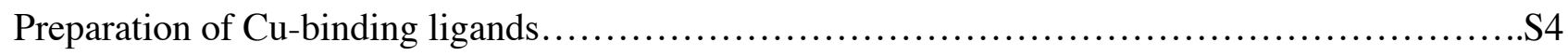

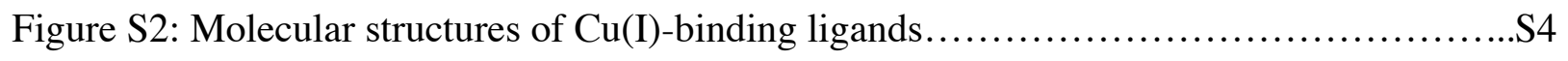

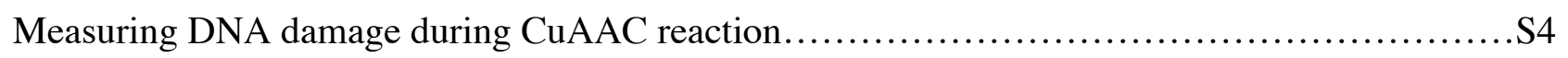

Measuring DNA damage during the surface-coupling reaction $\ldots \ldots \ldots \ldots \ldots \ldots \ldots \ldots \ldots \ldots \ldots \ldots . . . .55$

Figure S3: Schematic illustration of dual-amplification qPCR $\ldots \ldots \ldots \ldots \ldots \ldots \ldots \ldots \ldots \ldots . . . \ldots 7$

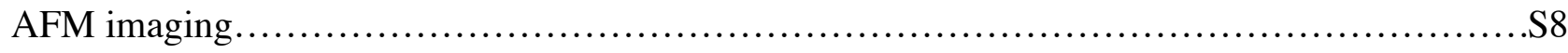

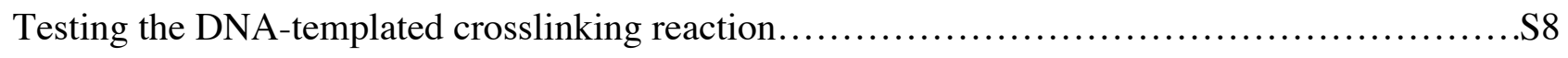

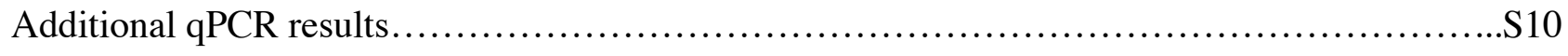

Figure S4: Results from qPCR measurements with HLTA ligand $\ldots \ldots \ldots \ldots \ldots \ldots \ldots \ldots \ldots . . . \ldots$

References.................................................................... 


\section{Materials and methods}

The following synthetic oligonucleotides were used in this study:

\begin{tabular}{|l|l|l|}
\hline Name & DNA Sequence \& Modifications & Purpose \\
\hline DCD-05 & cattgagggggattcaatg & forward primer (qPCR) \\
\hline DCD-02 & ttgaaataccgaccgtgtga & reverse primer (3.5kbp product) \\
\hline DCD-16 & taccacattcaactaatgcag & reverse primer (225bp product) \\
\hline SF-78 & cgtactgactgctcacgaggtagc/(C3)/tctgaactgtttaaagcatttgaggg & forward primer with ssDNA tail \\
\hline SF-3.6k & tccttgaaaacatagcgatagcttag & reverse primer (3.6kbp product) \\
\hline SF-88 & (Az)/cgtactgactgctcacgaggtagc & azide-modified oligo \\
\hline SF-89 & gtgagcagtcagtacg/(Oct-dU) & alkyne-modified oligo \\
\hline SF-17 & gctacctcgtgagcagtcagtacgtttt /(C11-SS) & disulfide-DNA anchor strand \\
\hline
\end{tabular}

Abbreviations for DNA modifications: $($ Oct-dU) $=$ octadiynyl deoxyuracil; $(\mathrm{Az})=$ azide; $(\mathrm{C} 3)=$ propyl spacer; $(\mathrm{C} 11-\mathrm{SS})=$ undecyl disulfide;

The undecyldisulfide-DNA (SF-17) was purchased from Biosearch technologies (Petaluma, CA, USA), and all other synthetic DNA oligonucleotides were purchased from Integrated DNA Technologies (Coralville, IA, USA). The purity of the custom ordered oligonucleotides was verified by the manufacturers using mass spectrometry, and the DNA was used without further purification. DNA was stored long-term at $-20^{\circ} \mathrm{C}$ and short-term at $4^{\circ} \mathrm{C}$ in phosphate buffer $(\mathrm{PB}, 20 \mathrm{mM}$ sodium phosphate, $\mathrm{pH} 7)$.

\section{Preparation of DNA template strands}

DNA templates for qPCR: DNA template strands were prepared by conventional PCR amplification from the M13 bacteriophage genome. To serve as a template for PCR, M13mp18 RF I DNA (New England Biolabs Inc, Massachusetts, USA) was linearized using the EcoRI restriction enzyme (New England Biolabs) and purified by agarose gel electrophoresis using a QIAquick gel extraction kit (QIAGEN, Limburg, Netherlands). For the PCR reaction, 50 pg of linearized M13 DNA was combined with Taq DNA polymerase master mix (Bioexpress, Utah, USA), along with 
$200 \mathrm{nM}$ each of the forward (SF-08) and reverse (SF-3.6k) primers in a $250 \mu \mathrm{L}$ PCR tube. Ultrapure water produced by a Barnstead Nanopure Diamond water purification system (Thermo Scientific, North Carolina, USA) was used to bring the solution up to a volume of $50 \mu \mathrm{L}$. Solutions were incubated through the following program on an thermal cycler (Eppendorf, Hamburg, Germany): an initial melting step of $94^{\circ} \mathrm{C}$ for $2 \mathrm{~min}$, followed by 30 cycles of melting at $94^{\circ} \mathrm{C}$ for $30 \mathrm{sec}$, annealing at $49^{\circ} \mathrm{C}$ for $45 \mathrm{sec}$, and extension at $70^{\circ} \mathrm{C}$ for $120 \mathrm{sec}$, followed by a final cycle with an extension of 5 minutes. Remaining primers and enzymes were removed using the QIAquick PCR Purification Kit (QIAGEN). Purified DNA templates were kept in TAE buffer at $4{ }^{\circ} \mathrm{C}$ for shortterm, and $-20^{\circ} \mathrm{C}$ for long-term storage $(1 \mathrm{X}$ TAE $=40 \mathrm{mM}$ Tris(hydroxymethyl)aminomethane acetate, $1 \mathrm{mM}$ EDTA, pH 8.3).

DNA templates with single-stranded tail for surface hybridization: In order to hybridize with the surface anchor strands, the double-stranded DNA targets contain a terminal 24-base singlestranded DNA tail segment that is complementary to the anchor strand sequence. The target strands are generated via polymerase chain reaction (PCR) with a forward primer that is connected to the 24-base tail by a propyl spacer group, which prevents the polymerase enzyme from copying over the tail region. Therefore, PCR can produce a double-stranded product with a short, single-stranded tail (see Figure S1). PCR was carried out with the same protocol that was described in the previous step (see DNA templates, above), using the SF-78/ SF-3.6K primer pair.

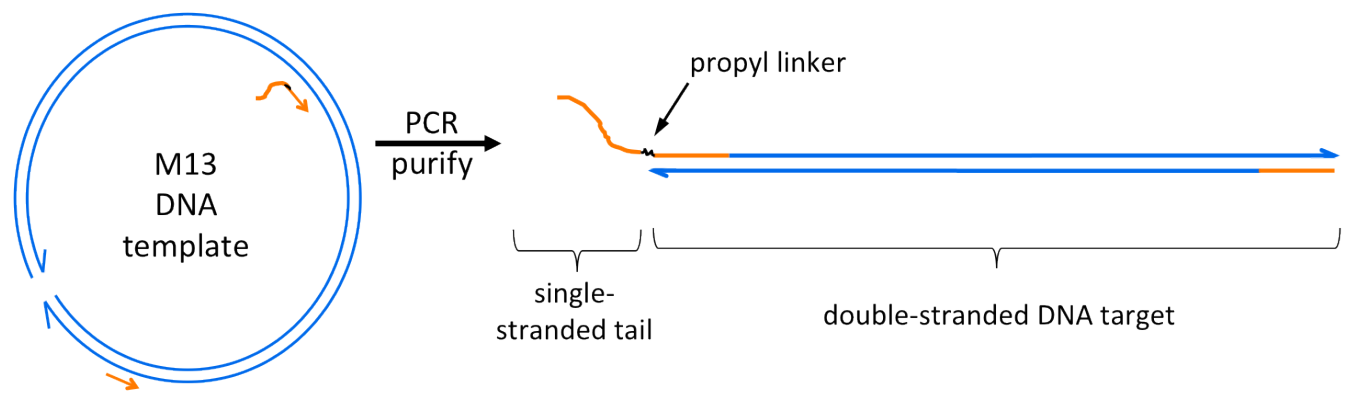

Figure S1: Generation of the double-stranded DNA targets via PCR with modified primers (primers in orange). 


\section{Preparation of the Cu-binding ligands}

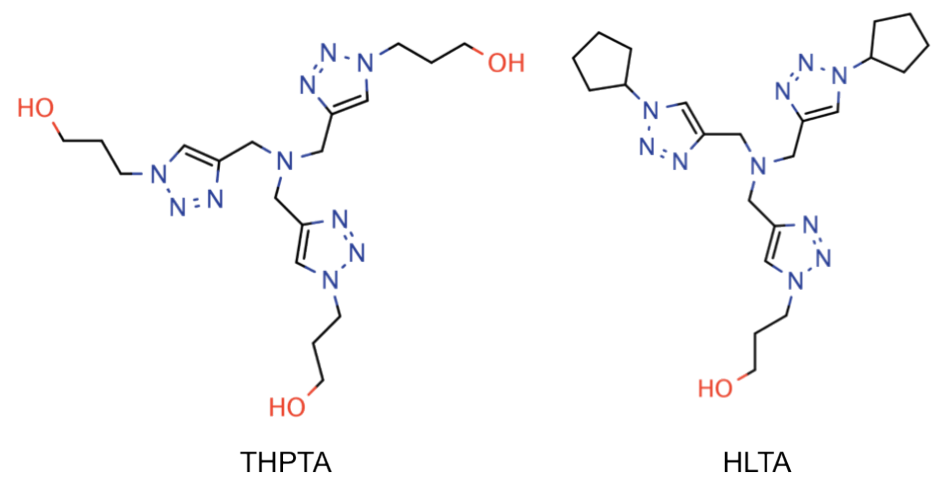

Figure S2: Molecular structures of the $\mathrm{Cu}(\mathrm{I})$-binding ligands used in this study.

THPTA: The tris(3-hydroxypropyltriazolylmethyl)amine ligand was purchased as a solid from Sigma Aldrich (St. Louis, MO, USA).

HLTA: The 3-(4-((bis((1-cyclopentyl-1H-1,2,3-triazol-4-yl)methyl)amino)methyl)-1H-1,2,3triazol-1-yl)propan-1-ol ligand was synthesized according to a previously published protocol. ${ }^{1}$

Preparation of catalyst solutions: The copper/ligand catalyst solutions were prepared at $2 \mathrm{X}$ working concentration by dissolving $\mathrm{Cu}$ (II) sulfate in water and mixing with a 2:1 molar ratio of the appropriate ligand (THPTA or HLTA) in either water or a water/DMSO mixture containing 40mM phosphate buffer (pH 7) and $400 \mathrm{mM} \mathrm{NaCl}$. Cu(II)/ligand solutions were stored at $4^{\circ} \mathrm{C}$ until use.

\section{Measuring DNA damage during CuAAC reaction}

DNA exposure to the Cu catalyst: The method for quantifying single-stranded DNA lesions that occurred during the $\mathrm{CuAAC}$ reaction was as follows. First, $10 \mu \mathrm{L}$ of the $2 \mathrm{X} \mathrm{Cu}(\mathrm{II}) /$ ligand solution was combined with $5.0 \mu \mathrm{L}$ of the DNA template $(4 \mathrm{ng} / \mathrm{uL}$ stock) in a $200 \mu \mathrm{L}$ PCR tube. Next, $5.0 \mu \mathrm{L}$ of a $4 \mathrm{X}$-concentrated solution of sodium ascorbate was added to initiate the reaction, and the solution was mixed and immediately capped. After the desired reaction time, a $2.0 \mu \mathrm{L}$ aliquot of the reaction was quenched by diluting in $1.0 \mathrm{~mL}$ in $0.1 \mathrm{X}$ TAE buffer $(4 \mathrm{mM}$ Tris acetate, $0.1 \mathrm{mM}$ EDTA, 
$\mathrm{pH} \sim 8$ ) on ice. Note that no effort was made to exclude oxygen during the reaction step, aside from capping the tube.

Quantitative polymerase chain reaction (qPCR): All qPCR reactions were prepared with at least 3 technical replicates. Each $20 \mathrm{uL}$ reaction contained the following: 1X Genemate Taq DNA polymerase Master Mix (BioExpress, Utah, USA), 200nM each of the forward (DCD-05) and reverse (DCD-02) primers, 0.15X Sybr Green I fluorescent dye (Life Technologies, New York, USA), and 5.0 $\mu \mathrm{L}$ of the diluted, quenched DNA/Cu reaction (see DNA exposure step, above). Reactions were prepared on ice in $0.1 \mathrm{~mL}$ clear plastic PCR tube strips (Qiagen). Quantitative PCR was carried out on a Rotorgene Q real-time PCR cycler (Qiagen), using a minimum of 32 cycles of the following temperature profile: denature at $95^{\circ} \mathrm{C}$ for $30 \mathrm{sec}$, anneal at $55^{\circ} \mathrm{C}$ for $20 \mathrm{sec}$, and extend at $71^{\circ} \mathrm{C}$ for $120 \mathrm{sec}$. Following completion of cycling, a melt analysis was performed by slowly ramping the temperature up to $95^{\circ} \mathrm{C}$ and continuously monitoring the fluorescence.

qPCR data analysis: For each qPCR reaction a threshold quantification cycle $\left(\mathrm{C}_{\mathrm{q}}\right)$ was defined as the fractional cycle at which the measured fluorescence intensity crosses a threshold value, which is chosen to correspond to a region in which the PCR is in the exponential amplification phase. For each sample, the relative DNA quantity $\varphi$, as compared to the reference sample, was determined by evaluating the following equation:

$$
\varphi=\frac{[D N A]}{[D N A]_{r e f}}=2^{-\Delta C_{q}}=2^{-\left(C_{q}-C_{q . r e f}\right)}
$$

where $\mathrm{C}_{\mathrm{q}}$ and $\mathrm{C}_{\mathrm{q} \text {.ref }}$ correspond to the sample and reference quantification cycles, respectively. The values reported are average values of at least three identical replicates for each sample.

\section{Measuring DNA damage during the surface-coupling reaction}

Preparation of DNA anchor surface: Carboxyl-terminated alkanethiol self-assembled monolayers containing short, thiolated DNA anchor strands (SF17) were prepared on a single crystal gold substrate, as described in a previous publication. ${ }^{2}$

Hybridization with the target DNA: The purified target DNA PCR product was diluted to approximately $1 \mathrm{ng} / \mu \mathrm{L}$ in the hybridization buffer $(\mathrm{HB}, 200 \mathrm{mM} \mathrm{NaCl}, 40 \mathrm{mM}$ Tris acetate, $1 \mathrm{mM}$ 
EDTA, 1.0mM sodium dodecyl sulfate, $\mathrm{pH} 8.3$ ), and was incubated with the DNA anchor surface for 20-30 minutes. After hybridization, the surface was rinsed repeatedly with HB to remove any unbound DNA.

DNA surface exposure to the $\mathrm{Cu}$ catalyst: The $\mathrm{Cu}(\mathrm{II}) /$ ligand catalyst solution was prepared as described earlier (see Preparation of catalyst solutions, above). Prior to the surface reaction, the surface was rinsed with PBS to thoroughly remove Tris and EDTA, both of which inhibit the reaction. ${ }^{3}$ Then the sodium ascorbate reducing agent was added to the $\mathrm{Cu}(\mathrm{II}) /$ ligand catalyst solution, and then the surface was immediately exposed to the resulting mixture. After the desired reaction time, the surface was rinsed repeatedly with saline TAE buffer (STAE, 200mM $\mathrm{NaCl}$, $40 \mathrm{mM}$ Tris acetate, $5 \mathrm{mM}$ EDTA, $\mathrm{pH} 8.3$ ). Note that no effort was made to exclude oxygen during this step.

Denaturation and collection of DNA: After exposure to the catalyst solution, the surface-bound DNA was denatured using alkaline conditions, which disrupt the hydrogen bonds in the base pairs and release the DNA from the surface. The surface was exposed to a $70 \mu \mathrm{L}$ aqueous solution of $10 \mathrm{mM} \mathrm{NaOH}$ and $330 \mu \mathrm{M}$ EDTA ( $\mathrm{pH}$ 12) for 5 minutes, which was then collected and neutralized by diluting 4:1 in TAE and stored at $-20^{\circ} \mathrm{C}$. It was then rinsed with the same solution to remove any free DNA.

qPCR of surface DNA: The protocol for qPCR with the collected surface DNA is the same as described in an earlier section (see Quantitative polymerase chain reaction, above). The collected, neutralized surface DNA (see previous section) was further diluted 9:1 in water, and was then used as the template for qPCR.

Dual-amplification qPCR: Relative quantification requires comparison of $\mathrm{C}_{\mathrm{q}}$ values to an untreated reference containing the same initial DNA quantity; however, the amount of DNA bound to the surface can vary from sample to sample. To compensate for this variation, qPCR was used for each surface DNA sample to separately amplify both the full-length $3.5 \mathrm{kbp}$ product (primer pair DCD-05/ DCD-02), and a shorter 200bp product (primer pair DCD-05/ DCD-16) from within the same template. Because of its much smaller footprint, the $200 \mathrm{bp}$ region is unlikely to be cleaved under conditions with a modest damage frequency, allowing the shorter product to serve as an internal reference (see Figure S3). ${ }^{4,5}$ After qPCR, the amount of intact, full-length DNA was divided by the total amount of DNA present in the sample, as determined using a standard 
calibration curve with the $200 \mathrm{bp}$ product. This ratio of intact/total DNA was then normalized by dividing by the corresponding ratio determined for the untreated control sample. This normalization process compensates for variation in surface coverage, as well as factoring out any difference in amplification efficiency between the two product lengths. Thus it allows for direct comparison between different samples and the untreated control. Note that the requirement for modestly damaging conditions prevented accurate quantification of surface DNA under conditions that caused extensive damage. In this case, the total amount of DNA would need to be carefully determined using an alternative method.

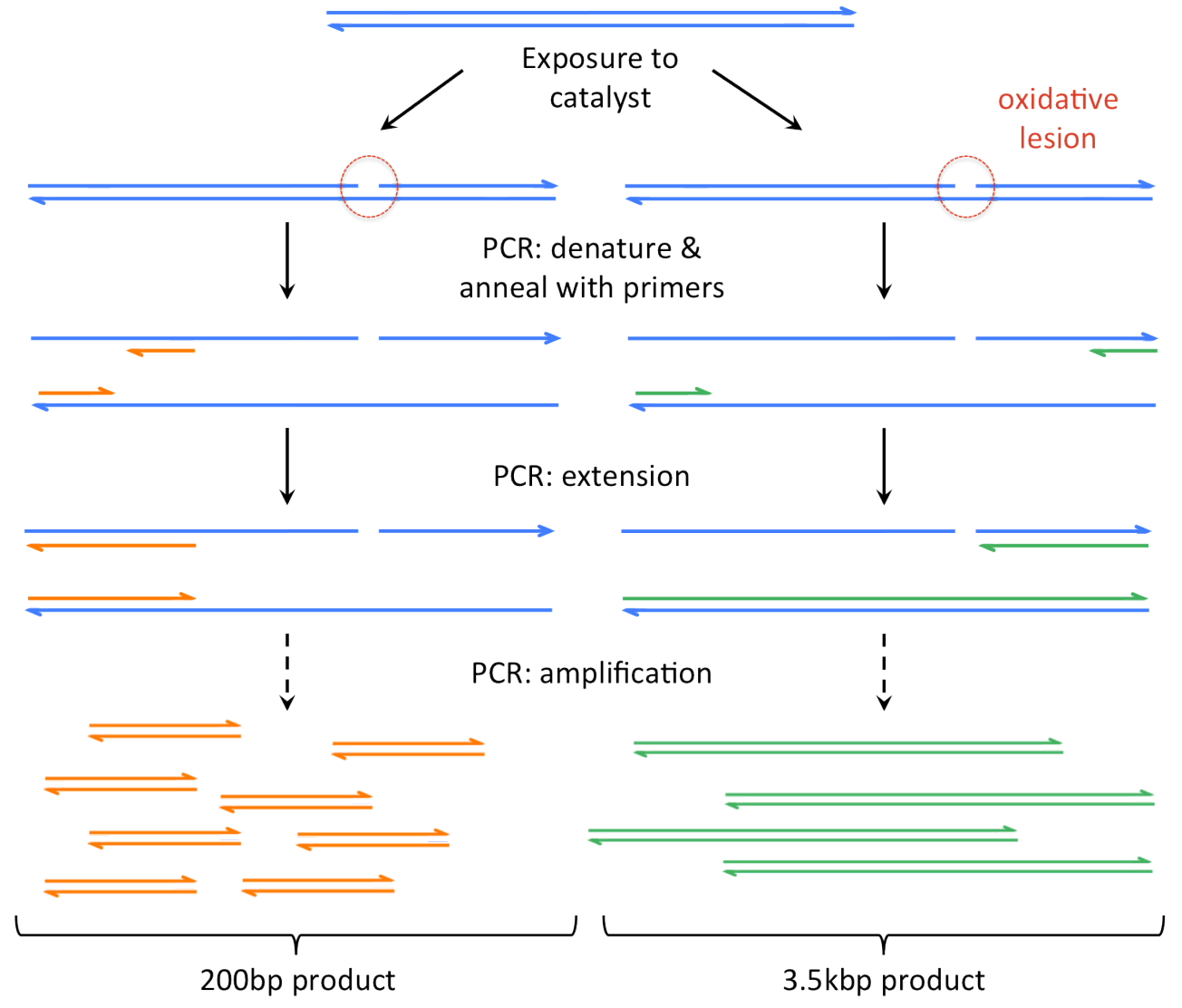

Figure S3: Schematic illustration of dual-amplification qPCR, which accounts for differences in total amount of DNA by amplifying both the long (3.5kbp, green) product, and a short (200bp, orange) region that is unlikely to be damaged. 


\section{AFM imaging}

All imaging was carried out using an NTEGRA Vita Atomic Force Microscope, manufactured by NT-MDT (Moscow, Russia). Images were acquired while operating in semi-contact (tapping) mode under an aqueous $\mathrm{Ni}(\mathrm{II})$ imaging buffer (NB, 5mM Ni(II) acetate, $0.1 \mathrm{X}$ TAE), using silicon tips mounted on silicon nitride cantilevers with a nominal spring constant of $0.3 \mathrm{~N} / \mathrm{m}$ and a resonant frequency of approximately $16 \mathrm{kHz}$ in liquid (model SNL-10, manufactured by Bruker, California, USA).

As described in a previous publication, ${ }^{2}$ the $\mathrm{Ni}$ (II) ions are coordinated by the surface carboxylate groups and function as salt bridges that immobilize the anionic DNA molecules. Prior to the hybridization, reaction, or denaturation steps, the surface was rinsed repeatedly with STAE to remove any $\mathrm{Ni}(\mathrm{II})$ ions that were bound to the surface.

A note on cleanliness: All glassware, teflon fluid cells, and ceramic tweezers were cleaned in piranha solution and rinsed thoroughly with water before use. (Piranha is 3:1 sulfuric acid: hydrogen peroxide. CAUTION - piranha is highly corrosive and reacts violently with organics).

\section{Testing the DNA-templated crosslinking reaction}

The efficiency of the CuAAC reaction for crosslinking two complementary DNA oligonucleotides was measured by carrying out the coupling reaction in solution, quenching the reaction at specified time points, and measuring the yield at each time point with denaturing polyacrylamide gel electrophoresis (D-PAGE), as described below.

Hybridization and reaction with copper: First the single-stranded, azide- and alkyne-modified DNA strands (SF-88 and SF-89, respectively) were hybridized by mixing in a 1:1 molar ratio in $0.8 \mathrm{M} \mathrm{NaCl}, 20 \mathrm{mM} \mathrm{PB}, \mathrm{pH}$, heating briefly to $70^{\circ} \mathrm{C}$, and cooling from $65^{\circ} \mathrm{C}$ to $22^{\circ} \mathrm{C}$ at a rate of $0.75^{\circ} \mathrm{C} / \mathrm{min}$ in a MJ-Mini thermal cycler (Bio-Rad Laboratories, Hercules, CA, USA). Then 7.5 $\mu \mathrm{L}$ of the hybridized DNA was added to $15 \mu \mathrm{L}$ of the $2 \mathrm{X} \mathrm{Cu}(\mathrm{II}) /$ ligand solution. Finally, $7.5 \mu \mathrm{L}$ of a $4 \mathrm{X}$ concentrated solution of sodium ascorbate was added to initiate the reaction, and the solution was mixed and immediately capped. The final volume was $30 \mu \mathrm{L}$, and the final DNA concentration was $1.25 \mu \mathrm{M}$. At specified time points, a $4.0 \mu \mathrm{L}$ aliquot of the reaction mixture was removed and added 
to $16 \mu \mathrm{L}$ of $1.25 \mathrm{X}$ quenching buffer $(1 \mathrm{X} \mathrm{QB}=3: 1$ formamide:water, $20 \mathrm{mM}$ Tris acetate, $2.5 \mathrm{mM}$ EDTA, 0.15X gel loading dye). The quenched reaction aliquot was immediately placed on ice and transferred to the freezer $\left(-20^{\circ} \mathrm{C}\right)$ until being denatured and loaded into the gel.

Denaturing polyacrylamide gel electrophoresis: Polyacrylamide gels were prepared with a polyacrylamide/bisacrylamide (29:1) concentration of $12-14 \%$, and contained $8.3 \mathrm{M}$ urea in order to denature the DNA during the gel runs. After casting the gel and setting for at least 30 min, the wells were rinsed with $0.5 \mathrm{X}$ TBE running buffer $(1 \mathrm{X}=89 \mathrm{mM}$ Tris base, $89 \mathrm{mM}$ boric acid, $2 \mathrm{mM}$ EDTA, $\mathrm{pH}$ 8.3). The gel was then pre-run in $0.5 \mathrm{X}$ TBE for at least $40 \mathrm{~min}$ at $150 \mathrm{~V}$ in an Enduro vertical gel electrophoresis system (Labnet International, Inc, New Jersey, USA). Prior to loading the gel, the samples were removed from the freezer and heated $>90^{\circ} \mathrm{C}$ in QB for $5 \mathrm{~min}$ to completely denature the DNA. They were then immediately loaded into the gel and run for 120 minutes at a voltage of $150 \mathrm{~V}$. An ice pack was included in the outer buffer chamber to reduce overheating, which causes distortion of the gel bands. After the run, the gels were removed and stained by soaking in $0.5 \mathrm{X}$ TBE containing a $1 \mathrm{X}$ concentration of Sybr Green II dye (Life Technologies, California, USA) for 15 min under gentle agitation. The gels were visualized and imaged on an Enduro Gel Documentation System (Labnet).

Determination of reaction yield from gel images: It has been demonstrated previously that the efficiency of DNA crosslinking reactions can be estimated by comparing band intensities from denaturing PAGE. ${ }^{6}$ Due to the urea content of the gel and the elevated temperatures during running, the DNA remains denatured as it runs through the gel. ${ }^{7}$ Any hybrid DNA that has successfully reacted will be crosslinked by the triazole product, and thus will migrate as a single, slower-moving product band, while any DNA that has not reacted will be separated into two different fastermoving bands (see Figure 2a, main text). We estimated the yield of the reaction at different time points using a custom MATLAB script, (The Mathworks, Inc., Massachusetts, USA), as follows. First, each product band was selected by the user and cropped out from the gel image. The average background pixel intensity was subtracted, and the total pixel intensity in the band area was then integrated. Finally, this integrated band intensity was normalized to that of a standard reference band on the same gel. This normalized intensity was plotted as the estimated yield (in arbitrary units) as a function of time, as shown in Figure $2 b$ (main text). It is worth noting that any of the product DNA that has been degraded during the reaction is expected to run faster than the intact 
product band due to a smaller size, and thus DNA degradation over time should also lead to a reduction in the apparent yield.

\section{Additional qPCR results}
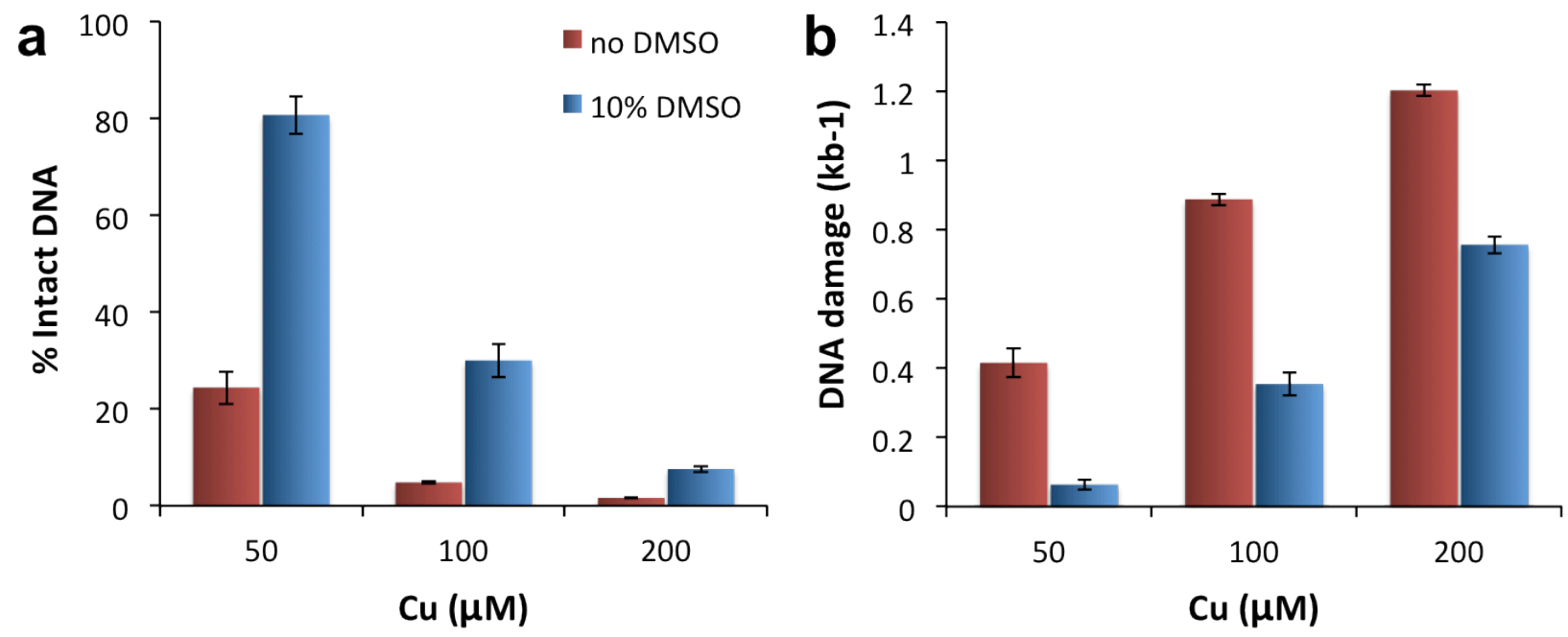

Figure S4: Results from qPCR measurements of oxidative DNA damage during the CuAAC reaction using the HLTA ligand. The percentage of intact DNA (a) and the corresponding DNA damage frequency (b) are plotted as a function of copper concentration, both with (blue) and without (red) $10 \%$ DMSO included in the reaction. For all reactions, $\mathrm{Asc}: \mathrm{Cu}=10: 1$ and $\mathrm{L}: \mathrm{Cu}=2: 1$, and the reaction time was 5 minutes. Error bars represent \pm the standard deviation of at least four identical qPCR replicates.

\section{REFERENCES}

(1) Abel, G. R., Cao, B. H., Hein, J. E. and Ye, T. (2014) Covalent, sequence-specific attachment of long DNA molecules to a surface using DNA-templated click chemistry. Chem. Commun. 50, 8131-8133.

(2) Abel Jr., G. R., Josephs, E. A., Luong, N. and Ye, T. (2013) A switchable surface enables visualization of single DNA hybridization events with atomic force microscopy. J. Am. Chem. Soc. 135, 6399-6402.

(3) Hong, V., Presolski, S. I., Ma, C. and Finn, M. G. (2009) Analysis and optimization of copper-catalyzed azide-alkyne cycloaddition for bioconjugation. Angew. Chem. Int. Ed. 48, 9879-9883.

(4) Ayala-Torres, S., Chen, Y., Svoboda, T., Rosenblatt, J. and Van Houten, B. (2000) Analysis of genespecific DNA damage and repair using quantitative polymerase chain reaction. Methods 22, 135-147.

(5) Hunter, S. E., Jung, D., Di Giulio, R. T. and Meyer, J. N. (2010) The QPCR assay for analysis of mitochondrial DNA damage, repair, and relative copy number. Methods 51, 444-451.

(6) Kocalka, P., El-Sagheer, A. H. and Brown, T. (2008) Rapid and efficient DNA strand cross-linking by click chemistry. Chembiochem 9, 1280-1285.

(7) Maniatis, T., Jeffrey, A. and and van deSande, H. (1975) Chain length determination of small doubleand single-stranded DNA molecules by polyacrylamide gel electrophoresis. Biochemistry 14, 3787-3794. 